\title{
Development and Validation of a Simple RP-HPLC Method for Determination of Naproxen in Pharmaceutical Dosage Forms
}

\author{
Saleha Tanjin ${ }^{1}$, Farhana Islam², Md. Zakir Sultan", Asma Rahman³, Sharmin Reza \\ Chowdhury $^{1}$, Tasnuva Sharmin ${ }^{1}$ and Mohammad A. Rashid ${ }^{2}$ \\ ${ }^{1}$ Department of Pharmacy, State University of Bangladesh, Dhanmondi, Dhaka, Bangladesh \\ ${ }^{2}$ Department of Pharmaceutical Chemistry, Faculty of Pharmacy, University of Dhaka, Dhaka-1000, Bangladesh. \\ ${ }^{3}$ Centre for Advanced Research in Sciences (CARS), University of Dhaka, Dhaka-1000, Bangladesh
}

\begin{abstract}
A simple, sensitive and precise reversed phase high performance liquid chromatographic (RP-HPLC) method has been developed for the estimation of naproxen in pharmaceutical dosage forms. The method was developed using the mobile phase comprising of dibasic sodium phosphate buffer $\left(\mathrm{Na}_{2} \mathrm{HPO}_{4}\right)$ at $\mathrm{pH} 7.80$ (adjusted by sodium hydroxide) and acetonitrile in the ratio of 70:30 (v/v) over C-18 column (250 x $4.6 \mathrm{~mm}, 5 \mu \mathrm{m}$, Phenomenex Inc.) at ambient temperature. The flow rate was at $0.7 \mathrm{ml} / \mathrm{min}$ and the column washing was monitored by UV detector at $225 \mathrm{~nm}$. The retention time of naproxen was $4.8 \pm 0.1 \mathrm{~min}$. The recovery was found to be $>97 \%$ which is demonstrative of accuracy of the protocol. Inter-day and intra-day precision of the newly developed method were less than the maximum allowable limit (RSD\% $\leq 2.0$ ) according to ICH, USP and FDA guidelines. The method showed linear response with correlation coefficient $\left(\mathrm{r}^{2}\right)$ value of 0.9991 . Therefore, the method was found to be accurate, reproducible, sensitive and less time consuming and can be successfully applied for routine analysis of naproxen in pharmaceutical formulations.
\end{abstract}

Key words: Naproxen, Validation, Reverse phase HPLC.

\section{Introduction}

Chemically, naproxen is (+)-(S)-2-(6-methoxynaphthalen-2-yl) propanoic acid (Figure 1). It is a member of the 2-arylpropionic acid family of NSAIDs. Naproxen has analgesic, anti-inflammatory and antipyretic activities, which are thought to be mediated via inhibition of the enzyme prostaglandin synthetase with consequent reduction in the synthesis of prostaglandins from arachidonic acid. Naproxen also inhibits platelet aggregation by inhibition of platelet thromboxane A2. Naproxen is also used in patients suffering from rheumatoid arthritis, osteoarthritis, juvenile arthritis, ankylosing spondylitis, tendonitis, bursitis and acute gout. It is comparable to aspirin and indomethacin in controlling disease activity with less frequent and milder side effects (Brunton et al., 2005). Literature survey revealed a few analytical methods like UV, LC-MS, HPTLC and HPLC for its analysis (Gondalia and Dharamsi, 2010; Shubhangi et al., 2010; Palavai et al., 2011; Haque et al., 2011; Mohideen et al., 2011; Sujana et al., 2012; Pakhuri et al., 2012). However, none of these methods are free from limitations. Most of the available methods are complex and expensive. Therefore, development of a simple and modified HPLC method for the estimation naproxen is highly desirable. The aim of the present study was to develop a simple and rapid RP- HPLC method for quantification of naproxen in pharmaceutical preparations and to validate that method according to ICH and FDA guidelines (Food and Drug Administration, 2012; United States Pharmacopeia (USP), 2007; International Conference on Harmonisation (ICH), 2005; Kayesh et al., 2013; Hossain et al., 2013; Akteruzzaman et al., 2012).

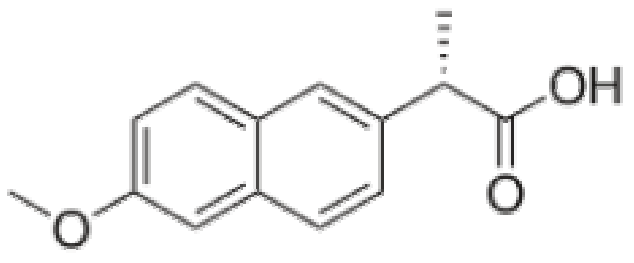

Figure 1. Structure of naproxen 


\section{Materials and Methods}

Reagents and chemicals: Working standard of naproxen was obtained from Drug International Ltd., Dhaka, Bangladesh, supplied by Aarti Drugs Ltd., Mumbai, India. The marketed formulations (tablets each containing $500 \mathrm{mg}$ of naproxen), buffer and HPLC grade acetonitrile were purchased from local market.

Instrumentation: High Performance Liquid Chromatographic system (Shimadzu-UFLC Prominence), equipped with an auto sampler (Model- SIL 20AC HT) and UV-Visible detector (Model-SPD 20A) was used for the analysis. The data were recorded using LC-solutions software.

Chromatographic conditions: Analytical reversed phase C-18 (ODS column, 250 x $4.6 \mathrm{~mm}, 5 \mu \mathrm{m}$, Phenomenex, Inc) was used for the separation. Mobile phase consisting of a mixture of buffer (dibasic sodium hydrogen phosphate, $\mathrm{pH} 7.80$ adjusted by sodium hydroxide) and acetonitrile in the ratio of $70: 30(\mathrm{v} / \mathrm{v})$ was delivered at a flow rate of $0.7 \mathrm{ml} / \mathrm{min}$ with UV detection at $225 \mathrm{~nm}$. The mobile phase was filtered through $0.22 \mu \mathrm{m}$ membrane filter, sonicated and degassed before use. Analysis was performed at room temperature $\left(\sim 26^{\circ} \mathrm{C}\right)$ temperature.

Method development: Mobile phase comprising of buffer and acetonitrile at different $\mathrm{pHs}$ and proportions were tried to achieve optimum separation. Finally buffer (disodium hydrogen phosphate, $\mathrm{pH} 7.80$ adjusted by sodium hydroxide) and acetonitrile (70: $30 \mathrm{v} / \mathrm{v})$ were selected as an appropriate developing medium which gave good resolution and met acceptable system suitability parameters.

Preparation of standard solutions: Standard naproxen (205.0 mg) was accurately weighed and transferred into a $50 \mathrm{ml}$ clean dry volumetric flask, and then water was added and sonicated for 5 minutes. The concentration of this preparation was $50 \mu \mathrm{g} / \mathrm{ml}$ and five different solutions were prepared having concentrations of $10 \mu \mathrm{g} / \mathrm{ml}, 20$ $\mu \mathrm{g} / \mathrm{ml}, 30 \mu \mathrm{g} / \mathrm{ml}, 40 \mu \mathrm{g} / \mathrm{ml}$ and $50 \mu \mathrm{g} / \mathrm{ml}$ to obtain the calibration curve. The solutions were filtered through 0.45 $\mu \mathrm{m}$ filter tips and $20 \mu \mathrm{L}$ of each solution were injected into chromatograph and the chromatograms were recorded.

Preparation of sample solutions: Ten tablets each containing $500 \mathrm{mg}$ naproxen were weighed and the average weight was calculated. The tablets were ground and powder equivalent to $2.4 \mathrm{mg}$ of naproxen was dissolved in $10 \mathrm{ml}$ water to make the concentration of the solution $240 \mu \mathrm{g} / \mathrm{ml}$. To ensure complete extraction of the drug it was sonicated for $5 \mathrm{~min}$ and $5 \mathrm{ml}$ of this solution was taken in a $10 \mathrm{ml}$ volumetric flask and water was added up to the mark. Final concentration of the solution was $120 \mu \mathrm{g} / \mathrm{ml}$ and from the solution various concentrations such as $4,7,17 \mu \mathrm{g} / \mathrm{ml}$ were prepared. The solutions were filtered through $0.45 \mu$ filter tips and analyzed by HPLC.

\section{Method validation}

Specificity: The specificity of the LC method was evaluated to ensure that there was no interference from the excipients present in the pharmaceutical product. The specificity was studied by injecting the excipients and standard solution of naproxen.

Linearity: Five solutions having concentrations of 10, 20, 30, 40 and $50 \mu \mathrm{g} / \mathrm{ml}$ were prepared. Then $20 \mu \mathrm{l}$ from each solution was injected using the auto-sampler and the analyses were monitored at $225 \mathrm{~nm}$ and repeated three times. The average peak areas were plotted against respective concentration. The linearity of the proposed method was evaluated by using calibration curves to calculate coefficient of correlation and intercept values.

Accuracy: The accuracy of the procedure is the nearest of the result obtained by the method to the true value. The accuracy is expressed by calculating the percent recovery (R\%) of analyte recovered by the assay. To evaluate the accuracy of the proposed method, successive analysis $(\mathrm{n}=2)$ for two different concentrations (11 and $23 \mu \mathrm{g} / \mathrm{ml}$ ) of standard naproxen solutions were carried out by using the proposed method. Hence, all parameters (e.g. Recovery, \% Recovery, Error, $\%$ Error) were within the expected (95-105\% Recovery) range.

Precision: Precision of the assay was assessed with respect to both repeatability and reproducibility. The precision of an analytical method is the degree of agreement among individual test results where the method is applied repeatedly to multiple samplings. It was demonstrated by intra-day and inter-day variation studies. In the precision studies, solutions of standard were repeated thrice in a day and three consecutive days and 
percent of relative standard deviation (\%RSD) for response factor was calculated. The developed method was found to be precise as the \%RSD values precision studies were $<2 \%$, respectively as recommended by ICH guidelines. It was checked using the formula [RSD (\%) = (Standard deviation/Mean) x $100 \%$ ]. In the current method development and validation protocol, precision was determined by using single concentration of $5 \mu \mathrm{g} / \mathrm{ml}$, $15 \mu \mathrm{g} / \mathrm{ml}$ and $25 \mu \mathrm{g} / \mathrm{ml}$ for standard solution of naproxen.

Sample analysis: To quantify the active drugs in finished pharmaceutical formulation, successive analysis $(n=3)$ of the sample solution of naproxen were analyzed by the proposed method and the contents were determined by using the calibration curves, and the formula,

$\mathrm{y}=\mathrm{mx}+\mathrm{c}$.

Where,

$\mathrm{y}=$ peak area of the analyzed sample $\mathrm{m}=$ slope of the calibration curve

$c=$ intercept of the calibration curve

$\mathrm{x}=$ concentration of the analyzed sample.

\section{Results and Discussion}

Recently, HPLC is the most convenient and accurate technique for analysis bulk and finished pharmaceutical products. A RP-HPLC method has been developed and validated as per ICH, USP and FDA guidelines for determination of naproxen by using the mobile phase comprising of dibasic sodium phosphate buffer $\left(\mathrm{Na}_{2} \mathrm{HPO}_{4}\right)$ at $\mathrm{pH} 7.80$ (adjusted by sodium hydroxide) and acetonitrile in the ratio of 70:30 (v/v) over C-18 column (250 x $4.6 \mathrm{~mm}, 5 \mu \mathrm{m}$, Phenomenex Inc.) at ambient temperature. The flow rate was at $0.7 \mathrm{ml} / \mathrm{min}$ and the eluent was monitored by UV detector at $225 \mathrm{~nm}$. The retention time of naproxen was $4.8 \pm 0.1 \mathrm{~min}$ (Figure 2).

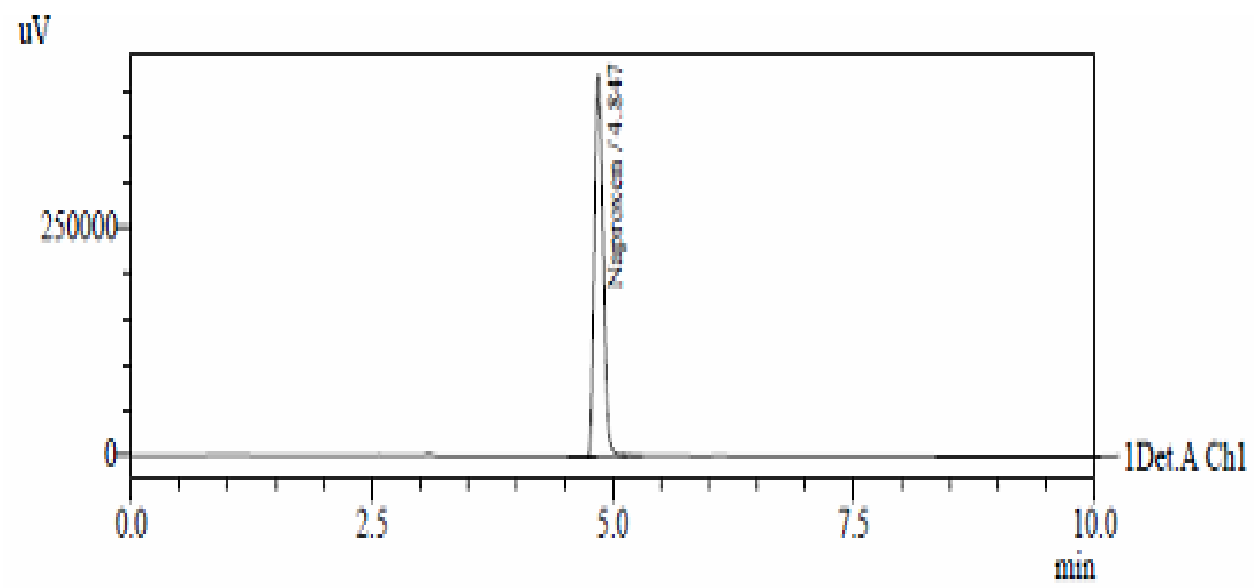

1 DetACh1/25inin

Figure 2. A chromatogram of naproxen

The proposed method was specific since excipients in the formulation did not interfere in the analysis. The method was found to be linear in the concentration range of 10 to $50 \mu \mathrm{g} / \mathrm{ml}$. When average peak areas were plotted against concentration levels a good correlation coefficient $\left(\mathrm{r}^{2}\right)$ was obtained as 0.9984 which were within the accepted range of guidelines and represented a good linear relationship of the newly developed method. The slope (m) and intercept (c) of the calibration curve was found to be as 156685 and 21277, respectively (Table 1, Figure 3).

Accuracy of the method was indicated by recovery values which were found to be $96.33 \%$ and $99.63 \%$.
Precision was reflected by \%RSD values and obtained as $0.18 \%, 0.10 \%$, and $0.13 \%$ which were found to be less than 2 suggesting sensitivity of the developed method (Table 2, 3).

Table 1. Linear regression data for calibration curve.

\begin{tabular}{lc}
\hline Parameter & Naproxen \\
\hline Linearity range $(\mu \mathrm{g} / \mathrm{ml})$ & $10-50$ \\
Correlation coefficient $\left(\mathrm{r}^{2}\right)$ & 0.9984 \\
Slope & 156685 \\
Intercept & 21277 \\
\hline
\end{tabular}


Table 2. Accuracy (\% recovery) results of naproxen.

\begin{tabular}{ccc}
\hline $\begin{array}{c}\text { Injected } \\
\text { conc. }(\mu \mathrm{g} / \mathrm{ml})\end{array}$ & $\begin{array}{c}\text { Recovered } \\
\text { conc. }(\mu \mathrm{g} / \mathrm{ml})\end{array}$ & \% recovery \\
\hline 11 & 10.59581 & 96.33 \\
23 & 22.91523 & 99.63 \\
\hline
\end{tabular}

Table 3. Intraday precision results of naproxen.

\begin{tabular}{ccccc}
\hline $\begin{array}{c}\text { Injected } \\
\text { conc. } \\
(\mu \mathrm{g} / \mathrm{ml})\end{array}$ & $\begin{array}{c}\text { Mean } \\
\text { recovered } \\
\text { conc. }(\mu \mathrm{g} / \mathrm{ml})\end{array}$ & $\begin{array}{c}\% \\
\text { recovery }\end{array}$ & SD & $\begin{array}{c}\% \\
\text { RSD }\end{array}$ \\
\hline 5 & 5.61775 & 112.36 & 0.01009745 & 0.18 \\
15 & 15.75191 & 105.01 & 0.01626886 & 0.10 \\
25 & 25.50662 & 102.03 & 0.03261645 & 0.13 \\
\hline
\end{tabular}

The method was applied for quantitative analysis of pharmaceutical preparation of naproxen formulated by local manufacturer. The quantity of active drug was determined for three preparations and the potency was found to be $97.13,97.97$ and $99.72 \%$, respectively (Table 4).

Table 4. \% Recovery of naproxen in marketed sample solution.

\begin{tabular}{ccc}
\hline $\begin{array}{c}\text { Injected } \\
\text { conc. }(\mu \mathrm{g} / \mathrm{ml})\end{array}$ & $\begin{array}{c}\text { Recovered conc. } \\
(\mu \mathrm{g} / \mathrm{ml})\end{array}$ & \% recovery \\
\hline 4 & 3.88504324 & 97.13 \\
7 & 6.85791107 & 97.97 \\
17 & 16.95273319 & 99.72 \\
\hline
\end{tabular}

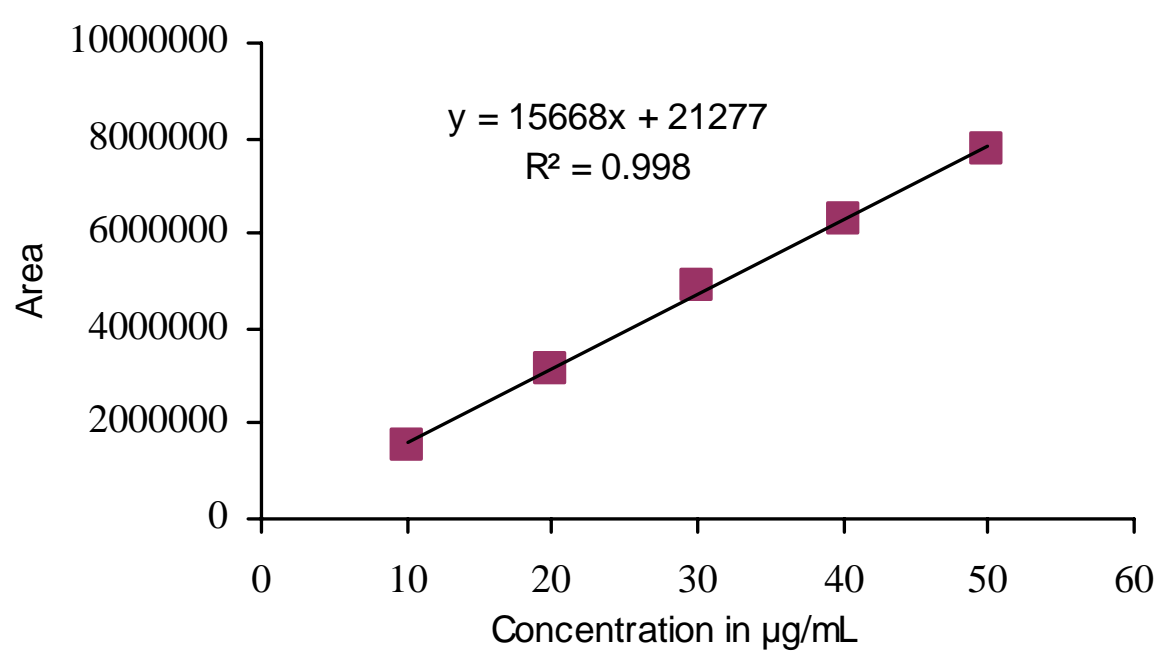

Figure 3. Calibration curve of naproxen

\section{Conclusion}

The developed RP-HPLC method was simple, sensitive, precise and accurate and hence can be used in routine analysis of naproxen in bulk as well as in pharmaceutical preparations.

\section{Acknowledgement}

The authors wish to thank to the authority of the Drug International Ltd. for providing the standard naproxen. The authors are also thankful to Centre for Advanced Research in Sciences (CARS), University of Dhaka, Dhaka-1000 for providing necessary facilities to perform these research.

\section{References}

Brunton, L. L., Lazo, J. S. and Parker, K. L. 2005. Goodman \&

Gilman's the pharmacological basis of therapeutics. McGrawHill Professional, New York, pp. 671-715. DOI: 10.1036/0071422803.

Gondalia, R. P. and Dharamsi, A. P. 2010. Spectrophotometric simultaneous estimation of naproxen sodiumand sumatriptan succinate in tablet dosage forms. Int. J. Pharm. Biomed. Sci. 1, 24-26.

Shubhangi, M., Bharat, S. and Ravindra, Y. 2010. Validated

HPTLC method for simultaneous quantization of domperidone maleate and naproxen sodium in bulk drug and formulation. Eurasian J. Anal. Chem. 5, 284-292. 
Palavai, S. R., Shakil, S., Gururaj, V., Badri, V. and Jayapal, V.P.S. 2011. Stability indicating simultaneous estimation of assay method for naproxen and esomeprazole in pharmaceutical formulations by RP-HPLC. Der. Pharma. Chemica 3, 553-564.

Haque, M.A., Shahriar, M., Parvin M.N. and Islam, S.M.A. 2011. Validated RP-HPLC method for estimation of ranitidine hydrochloride, domperidone and naproxen in solid dosage form. Asian J. Pharm. Ana. 1, 59-63.

Mohideen, S., Shivakanth, M., Kumar, P.S., Krishnan, S.N., Surendranath, Y. and Satyanarayana, T. 2011. Development and validation of analytical method for naproxen and pantoprazole in capsule dosage form. Der Pharmacia Sinica 2, 114-121.

Sujana, K., Sankar, D.G. and Abbulu, K. 2012. Simultaneous estimation of sumatriptan succinate and naproxen sodium by reverse phase HPLC in bulk and pharmaceutical dosage form. Inter. J. Pharm. Sci. Res. 3, 3433-3437.

Pakhuri, M., Chandra, S., Deepak, N., Ranawat, M. S. 2012. Development and validation of related substances by HPLC for analysis of naproxen in naproxen tablet formulations. Inter. J. Pharm. Sci. Drug Res. 4, 63-69.

Food and Drug Administration: Validation and verification guidance for human drug analytical methods (appendix 1), Document No.: ORA-LAB.5.4.5, Version No.: 1.6, pp. 1719, Revised: 01-25-2012; Website: http://www.fda.gov/ downloads/ScienceResearch/FieldScience/UCM092147. pdf; Date of download: 22/01/2013.
International Conference on Harmonisation (ICH), 2005. Harmonised Tripartite Guideline: Validation of Analytical Procedures: Methodology (Q2B), 2005.

United States Pharmacopeia (USP), 2007.Validation of compendial methods, Section 1225. USP 30. United States Pharmacopeial Convention, Rockville, MD, 2007.

Kayesh, R., Rahman, A., Sultan, M. Z., Uddin, M.G., Aktar, F. and Rashid, M. A. 2013. Development and validation of a RP-HPLC method for the quantification of omeprazole in pharmaceutical dosage form. J. Sci. Res. 5, 335-342.

Hossain, K., Rahman, A., Sultan, M. Z., Islam, F., Akteruzzaman, M., Salam, M. A. and Rashid, M. A. 2013. A validated RP-HPLC method for simultaneous estimation of antidiabetic drugs pioglitazone $\mathrm{HCl}$ and glimepiride. Bangladesh Pharm. J. 6, 69-75.

Akteruzzaman, M., Rahman, A., Sultan, M. Z., Islam, F., Salam, M. A. and Rashid, M. A. 2012. Development and validation of a simple RP-HPLC method for simultaneous estimation of metformin hydrochloride and rosiglitazone in pharmaceutical dosage forms. Dhaka Univ. J. Pharm. Sci. 11, 157-163. 